\section{Is flossing a waste of time?}

In early August dental flossing hit the mainstream headlines following news that the United States health department has removed daily flossing from its list of dental recommendations, due to a lack of evidence to support its effectiveness. The NHS is now reviewing its guidance on flossing the teeth.

A US investigation found that there is no proof that flossing prevents gum disease or stops cavities. Despite this, American dentists have recommended the use of floss to patients since the late $1800 \mathrm{~s}$.

The British Dental Association's (BDA's) scientific adviser, Professor Damien Walmsley, was widely quoted as saying that floss can be 'of little value', and that small interdental brushes are preferable for cleaning the area in between the teeth, where is space to do so.

'It is important to tell people to do the basics, said Professor Walmsley. 'Flossing is not part of the basics?

The dental fraternity quickly responded to highlight and emphasise the importance of regular interdental cleaning.

Michaela ONeill, President of the BSDHT,

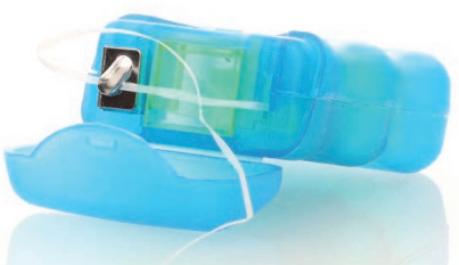

said that reports that flossing can actually be damaging to oral health are misleading and commented: 'Although there has been no conclusive proof to show that flossing is beneficial to oral health, there is evidence which shows that regular interdental cleaning with interdental brushes plays an important role in our oral health routine. Regular interdental cleaning removes the biofilms that develop in-between teeth.

This is commonly called plaque and hosts various microorganisms which, if left in situ, can lead to dental decay. It is this plaque that we aim to remove daily'.

A wider round-up of views on flossing was due to be published in the British Dental Journal on 26 August. Look out for a link on the BDJ Team Facebook page www. facebook.com/bdjteam.

\section{James is}

\section{new D'TA}

\section{president}

James Green has been

elected the ninth

president of the

Dental Technologists

Association (DTA),

the professional

representative body for dental technologists in the UK.

James authored the $B D J$

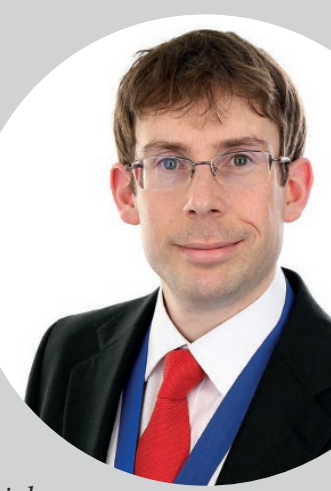

Team articles Dental materials:

The multi-stranded wire retainer (April

2015) and Dental materials: The Adams

family (December 2014). He is currently a maxillofacial and dental laboratory manager for London's Great Ormond Street Hospital for Children and the North Thames Cleft Centre, a supra-regional network for patients with clefts of the lip and palate from North London, Essex and South and West Hertfordshire. This service is run jointly by Great Ormond Street and the St Andrew's Centre for Plastic Surgery at Broomfield Hospital near Chelmsford so he also works there for part of the time.

James trained at Barts and the London, Queen Mary's School of Medicine and Dentistry in association with Lambeth College and qualified in 2001. After a vocational training year at the Royal London Hospital he spent the following two years at the Eastman Dental Hospital, part of the University College London Hospitals NHS Trust, before transferring to Great Ormond Street in 2004.

James has been the recipient of several awards including the Quintessence Book Prize for the best student from a London teaching hospital, the British Orthodontic Society Technicians Award and the Fellowship of the Orthodontic Technicians Association.

http://www.dta-uk.org
The British Society of Dental Hygiene and 'The Smile Factory' advert misleading and irresponsible for its portrayal of sugary and smiling.

The advertising campaign suggests Randoms, Jelly Tots, Tooty Frooties and Fruit Gums is good for your smile and is calling for more health considerations to be made when advertising sugary foods.

Michaela ONeill, President of the BSDHT, says sweet manufacturers must have an ethical responsibility to safeguard public health: 'While many of us will suffer from having a "sweet tooth" and enjoy sugar in moderation, having an advertising campaign positively linking sugary sweets to the smile is dangerous and reckless.

'Not only does the name of this campaign imply that sweets are good for smiles, by proxy it also positively links sugar with good oral health. The manufacturer behind it should have taken greater steps to act more responsibly for the benefit of the

Rowntree's Fruit Pastilles contain more made up of more than $70 \%$ sugar.

The BSDHT is now urging the advertising watchdog to investigate the campaign and has expressed their surprise regarding its advertising was singled out as a priority by advisers at Public Health England.

'As dental hygienists and dental therapists we see first-hand the damage that sugar causes, and particularly with children the results can be heart-breaking. Advertising bans on sugary foods and drinks, along with more broadcasting promoting healthier alternatives, will give people in the UK the best possible chance of a healthy life and reduce the amount of sugar we consume,' says Ms ONeill.

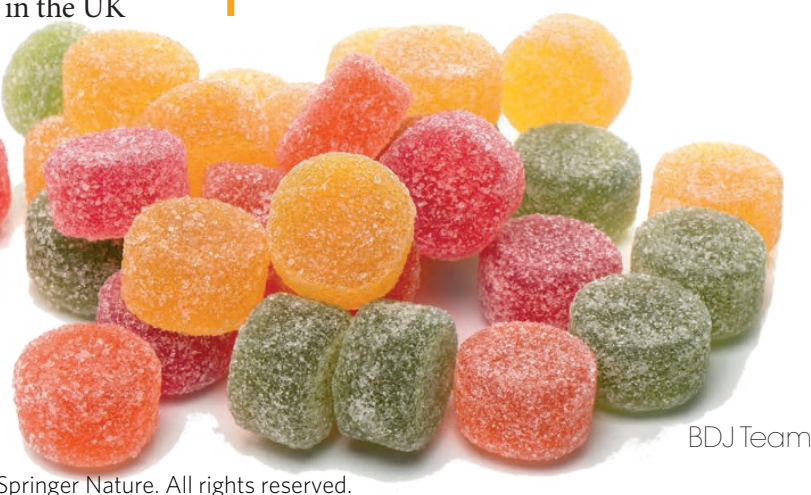

